\title{
First detection of Cryptosporidium spp. in red-bellied tree squirrels (Callosciurus erythraeus) in China
}

Yijun Chai ${ }^{a}$, Lei Deng ${ }^{a}$, Haifeng Liu ${ }^{a}$, Jingxin Yao, Zhijun Zhong, Leiqiong Xiang, Hualin Fu, Liuhong Shen, Ziyao Zhou, Junliang Deng, Yanchun Hu, and Guangneng Peng*

The Key Laboratory of Animal Disease and Human Health of Sichuan Province, College of Veterinary Medicine, Sichuan Agricultural University, Chengdu, Sichuan, 611130, PR China

Received 21 January 2019, Accepted 22 April 2019, Published online 13 May 2019

\begin{abstract}
Cryptosporidium spp. are opportunistic pathogens that cause diarrhea in a variety of animal hosts. Although they have been reported in many animals, no information has been published on the occurrence of Cryptosporidium spp. in red-bellied tree squirrels (Callosciurus erythraeus). A total of 287 fecal specimens were collected from Sichuan province in China; the prevalence of Cryptosporidium spp., measured by nested-PCR amplification of the partial small-subunit (SSU) rRNA gene, was 1.4\% (4/287). Three different Cryptosporidium species or genotypes were identified: Cryptosporidium parvum $(n=1)$, Cryptosporidium wrairi $(n=1)$, and Cryptosporidium rat genotype II $(n=2)$. The present study is the first report of Cryptosporidium infection in red-bellied tree squirrels in China. Although there is a relatively low occurrence of Cryptosporidium, the presence of C. parvum and C. wrairi, which were previously reported in humans, indicates that red-bellied tree squirrels may be a source of zoonotic cryptosporidiosis in China.
\end{abstract}

Key words: Cryptosporidium, Zoonosis, Red-bellied tree squirrel, Callosciurus erythraeus, SSU rRNA.

Résumé - Première détection de Cryptosporidium spp. chez des écureuils à ventre rouge (Callosciurus erythraeus) en Chine. Les Cryptosporidium spp. sont des agents pathogènes opportunistes qui provoquent une diarrhée chez divers animaux hôtes. Bien qu'ils aient été signalés chez de nombreux animaux, aucune information n'a été publiée sur la présence de Cryptosporidium spp. chez les écureuils à ventre rouge (Callosciurus erythraeus). Au total, 287 spécimens fécaux ont été recueillis dans la province du Sichuan en Chine. La prévalence de Cryptosporidium spp., mesurée par amplification par PCR imbriquée du gène partiel de la petite sous-unité de l'ARNr (SSU), était de 1,4\% (4/287). Trois espèces ou génotypes différents de Cryptosporidium ont été identifiés: Cryptosporidium parvum $(n=1)$, Cryptosporidium wrairi $(n=1)$ et le génotype II de Cryptosporidium du rat $(n=2)$. La présente étude est le premier signalement d'infection à Cryptosporidium chez des écureuils à ventre rouge en Chine. Cryptosporidium est relativement peu présent, mais la présence de $C$. parvum et de $C$. wrairi, déjà signalés chez l'homme, indique que les écureuils à ventre rouge peuvent être une source de cryptosporidiose zoonotique en Chine.

\section{Introduction}

Cryptosporidium spp. are causative agents of cryptosporidiosis and common intracellular parasites that can infect a wide range of vertebrates, including humans [4]. Humans and other animals are mainly infected via the fecal-oral route, directly from infected humans or animals or indirectly from food or water contaminated by feces of infected hosts [4, 28]. In humans, Cryptosporidium infection can be asymptomatic or

*Corresponding author: 976502406@qq. com

${ }^{\text {a }}$ These authors have contributed equally to this work. cause mild symptoms in immunocompetent individuals; however, in infants, young animals, and immunocompromized individuals, it may cause fatal and chronic diarrhea $[3,6,7]$.

Based on molecular epidemiologic surveys of cryptosporidiosis in different host species, at least 31 valid species and more than 70 genotypes are recognized, with new genotypes continually being found [9]. Among them, the most common causative agents for cryptosporidiosis are C. hominis, C. parvum, C. ubiquitum, and $C$. meleagridis, though nearly 20 Cryptosporidium species and genotypes have been reported in humans $[11,25]$. Some species of Cryptosporidium are 
host-adapted and have a narrow host range, such as $C$. muris, $C$. andersoni, and $C$. suis, mainly infecting rodents, cattle, and pigs, respectively, whereas $C$. parvum and $C$. ubiquitum have been identified in various animals $[2,18]$.

In China, Cryptosporidium spp. have been reported in humans, animals, and water samples; however, only limited reports on pet squirrels are available, and their role as reservoirs of infection for humans and other animals is unknown [10]. Red-bellied tree squirrels (Callosciurus erythraeus) are common companion animals closely associated with humans, and a previous study identified that they can harbor the human pathogen Enterocytozoon bieneusi [8]. Therefore, the main objective of this study was to determine the occurrence and the species/genotypes of Cryptosporidium in red-bellied tree squirrels and to assess their public health significance.

\section{Materials and methods Ethics}

The present study protocol was reviewed and approved by the Research Ethics Committee and the Animal Ethics Committee of Sichuan Agricultural University. Permission was obtained from the owners or shop managers before the fecal specimens were collected.

\section{Sample collection}

Two hundred eighty-seven fresh fecal specimens from red-bellied tree squirrels were collected from four pet markets between March 2017 and September 2018 in Sichuan province, China. Each red-bellied tree squirrel was kept in a separate cage in four pet markets. Approximately 30-50 g fresh fecal samples were collected from the bottom of each cage after defecation using sterile disposal latex gloves and then immediately placed into individual disposable plastic tubes. The fecal samples were transported to the laboratory with ice packs within $24 \mathrm{~h}$ of collection. No obvious clinical signs were observed during the sampling process. All fecal samples were stored in $2.5 \%$ potassium dichromate at $4{ }^{\circ} \mathrm{C}$ prior to DNA extraction.

\section{DNA extraction}

Each fecal specimen was sieved, and the filtrates were concentrated and washed three times with distilled water by centrifugation for $10 \mathrm{~min}$ at $1500 \mathrm{~g}$. Genomic DNA from fecal samples was extracted using the EZNA ${ }^{\circledR}$ Stool DNA Kit (Omega Bio-tek, Norcross, GA, USA), according to the manufacturer's recommended procedure. DNA was eluted in $200 \mu \mathrm{L}$ Solution Buffer from the kit and stored at $-20{ }^{\circ} \mathrm{C}$ until polymerase chain reaction (PCR) analysis.

\section{Genotyping of Cryptosporidium spp.}

A nested PCR targeting a 830-bp fragment of the SSU rRNA sequence was used to determine the Cryptosporidium species/genotype. The primers were F1 (5'-CCCATTTCCTTCGAAACAGGA- $\left.3^{\prime}\right)$ and R1 (5'-TTCTAGAGCTAATACATGCG-3') for the primary PCR and F2 (5'-AAGGAGTAAGGAACAACCTCCA-3') and R2 (5'-GGAAGGGTTGTATTATTAGATAAAG- $3^{\prime}$ ) for the secondary PCR [29]. The annealing temperature $\left({ }^{\circ} \mathrm{C}\right)$ was $55^{\circ} \mathrm{C}$ and $58{ }^{\circ} \mathrm{C}$ for the primary and secondary PCRs, respectively. TaKaRa Taq DNA Polymerase (TaKaRa Bio Inc., Tokyo, Japan) was used for the PCR amplifications. Positive and negative controls were included in each amplification. Secondary PCR products were subjected to electrophoresis in a $1.5 \%$ agarose gel and visualized by staining the gel with ethidium bromide.

\section{Sequence analysis}

All secondary PCR products of the expected size (about $830 \mathrm{bp}$ ) were directly sequenced at the BioSune Biotechnology Company (Shanghai, China) using an ABI 3730 DNA Analyzer (Applied Biosystems, Foster City, CA, USA). The nucleotide sequences of each obtained in the present study were aligned and analyzed using the Basic Local Alignment Search Tool and Clustal X (http://www.clustal.org/), with reference sequences retrieved from GenBank to identify Cryptosporidium species/genotypes [26].

\section{Phylogenetic analyses}

To support the grouping of a genotype, a phylogenetic relationship was assessed using the Phylip package, version 3.69 [24]. Based on the calculated evolutionary distances, neighbor-joining trees were constructed at each locus using the Kimura two-parameter model. Phylograms were drawn using MEGA 6.0 software. The MegAlign program in the DNA Star software package (version 5.0) was used to determine the degree of sequence identity. The unique partial nucleotide sequences of the SSU rRNA were deposited in the GenBank database under accession numbers MF327253, MF327254, and MK135778.

\section{Statistical analysis}

The chi-squared test was used to compare the occurrence of Cryptosporidium spp. between different pet markets. Differences were considered statistically significant when $p<0.05$.

\section{Results}

\section{Occurrence of Cryptosporidium spp.}

The overall occurrence of Cryptosporidium spp. in pet redbellied tree squirrels was $1.4 \%$ (4/287; 95\% CI [0.03-2.75]). The occurrences in pet markets no. 1-4 were $3.4 \%(2 / 59)$, $1.22 \%(1 / 85), 0 \%(0 / 64)$, and $1.27 \%$ (1/79), respectively, suggesting that the presence of Cryptosporidium spp. is generally uncommon (Table 1). The occurrence of Cryptosporidium spp. between the four markets were not significant $\left(\chi^{2}=2.654\right.$, $d f=3, p>0.05)$. 
Table 1. Occurrence and species/genotypes of Cryptosporidium in pet red-bellied tree squirrels from different sources in Southwestern China.

\begin{tabular}{lccccl}
\hline Source & $\begin{array}{c}\text { No. of } \\
\text { examined }\end{array}$ & $\begin{array}{c}\text { No. of } \\
\text { positive }\end{array}$ & $\begin{array}{c}\text { Occurrence } \\
(\%)\end{array}$ & $\begin{array}{c}95 \% \text { confidence } \\
\text { intervals }\end{array}$ & Species/genotypes $(n)$ \\
\hline Pet market 1 & 59 & 2 & 3.40 & $-0.012-0.080$ & Cryptosporidium rat genotype II (2) \\
Pet market 2 & 85 & 1 & 1.22 & $-0.011-0.035$ & C. wrairi (1) \\
Pet market 3 & 64 & 0 & 0 & & \\
Pet market 4 & 79 & 1 & 1.27 & $-0.012-0.037$ & C. parvum (1) \\
Total & 287 & 4 & 1.39 & $0.0003-0.028$ & $\begin{array}{c}\text { Cryptosporidium rat genotype II (2), } \\
\text { C. wrairi (1), C. parvum (1) }\end{array}$ \\
\hline
\end{tabular}

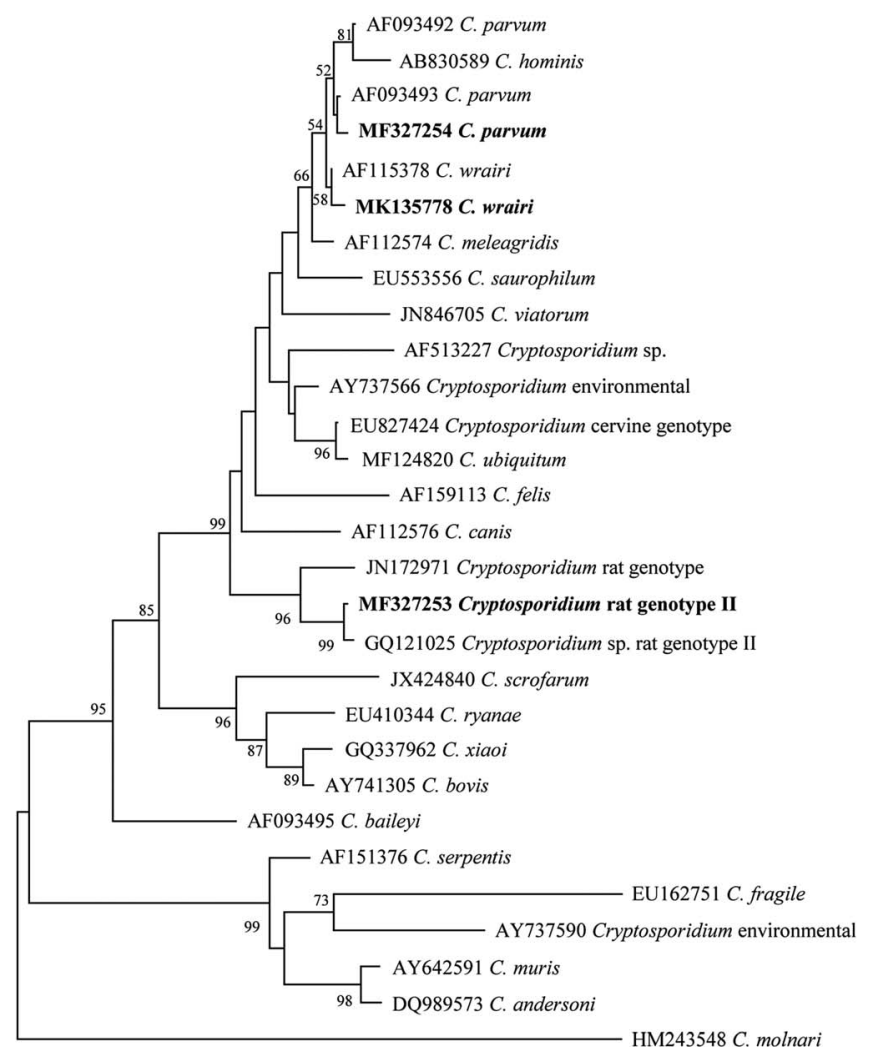

0.01

Figure 1. Phylogenetic relationship of Cryptosporidium red-bellied tree squirrel isolates in this study to other known Cryptosporidium species inferred by neighbor-joining analysis of the $18 \mathrm{~S}$ rRNA gene based on evolutionary distances calculated using the Kimura 2parameter model. Bootstrap values were obtained using 1000 pseudo-replicates, with only values above $50 \%$ reported.

\section{Cryptosporidium species/genotypes}

Four Cryptosporidium-positive samples were successfully sequenced, and three Cryptosporidium species/genotypes were identified based on sequence analysis of the SSU rRNA gene (Fig. 1). The nucleotide sequences of no. 30 and no. 32 are the same, and the two fecal samples were taken from two red-bellied tree squirrels in pet market 1 . In the SSU rRNA gene, there were 1-4 nucleotide differences between the redbellied tree squirrel isolates and other known Cryptosporidium rat genotypes and $C$. parvum isolates. Nucleotide sequence comparison revealed genetic diversity between the two sequences from isolates 30 and 44 . Isolate 30 contained four single-nucleotide polymorphisms (SNPs) within the 288289 bp and 464-465 bp regions of the SSU rRNA gene sequence of Cryptosporidium (deletions: A/A, T/C), whereas isolate 44 contained four SNPs within the $37 \mathrm{bp}$ (transversions: A/T), 38-39 bp (deletion: TA), and 702 bp (addition: T) regions compared to the rat Cryptosporidium variant JX294365, with which it shared $99.36 \%$ homology. Isolate 44 had $99.86 \%$ homology with the partial sequence of the $18 \mathrm{~S}$ ribosomal RNA gene of the C. parvum isolate KU198182. Isolate 60 shared $99.63 \%$ homology to the guinea pig C. wrairi isolate from Atlanta, USA (U11440).

\section{Discussion}

Cryptosporidium spp. have been reported in rodents from nine different countries, including developed countries (USA, Australia, Japan, Slovak Republic, and Italy) and developing countries (Philippines, Iran, Nigeria, and China) [12, 22, 23]. Additionally, Cryptosporidium spp. has been detected in various rodent species. In this study, the occurrence of Cryptosporidium spp. was $1.4 \%$, which is consistent with previous reports on the laboratory rat in Nigeria $(2 / 134,1.5 \%)$ [1], laboratory mouse $(4 / 229,1.7 \%)$ and bamboo rat $(3 / 92,3.3 \%)$ in China [17], and brown rat in Iran $(6 / 91,6.6 \%)$ [19]. However, the occurrence in this study was lower than that in pet chinchillas in China $(10 \%, 14 / 140)$, the Asian house rat in the Philippines $(44.6 \%, 37 / 83)$, striped field mouse in the Slovak Republic $(33 \%, 34 / 103)$, and red squirrel in Italy $(24.3 \%$, 17/70) $[16,20,23]$. These differences may be explained by many factors, such as the number of samples, different geography of the source region, host health status, and raising management system. In this study, a relative lower occurrence of Cryptosporidium spp. may be due to the fact that red-bellied tree squirrels were kept in a separate cage and have a lower feeding density, which contribute to reducing the transmission possibility between infected squirrels and other squirrels.

Currently, five Cryptosporidium species (C. parvum, C. muris, C. andersoni, C. ubiquitum, and C. wrairi) and nine Cryptosporidium genotypes (mouse genotype I, rat genotypes II-IV, ferret genotype, suis-like genotype, C. hominis monkey genotype II, chipmunk genotype III, and hamster genotype) have been reported in various rodents in China [6, 13, 31]. Among them, $C$. parvum is the most common zoonotic Cryptosporidium species and has been found in humans 
worldwide [10, 29]. It is a zoonotic pathogen and has been reported in humans as well as in many animals in China, such as cattle, dogs, horses, birds, giant pandas, red pandas, deer, snakes, and rodents $[15,27,30]$. Cryptosporidium rat genotype II has been found in brown rats in the Philippines [20], Nigeria [1], Australia [21], and China. C. wrairi was first detected in rodents in guinea pigs in China [5].

Phylogenetic trees were constructed for the SSU rRNA locus of the four red-bellied tree squirrel isolates (Fig. 1). Similar topologies were produced in neighbor-joining trees for the SSU rRNA locus, and the four isolates (two Cryptosporidium rat genotype II, one $C$. parvum, and one $C$. wrairi) referenced from GenBank formed a cluster supported by bootstrap values. Thus, based on our genotyping data, four isolates from this study represent Cryptosporidium rat genotype II, one $C$. parvum, and one $C$. wrairi. Despite considerable research on Cryptosporidium spp., only a few genetic studies have documented their occurrence in rodents; therefore, redbellied tree squirrels, similarly to other rodents, may play a role in the transmission of Cryptosporidium to humans [14].

In conclusion, this is the first report of Cryptosporidium spp. in red-bellied tree squirrels in China. Three species/ genotypes were identified: $C$. parvum, $C$. wrairi, and Cryptosporidium rat genotype II. Due to $C$. parvum having been reported in humans, our findings suggest that red-bellied tree squirrels may act as potential reservoirs for zoonotic Cryptosporidium spp. for transmission to humans. Moreover, due to the widespread practice of keeping pet rodents in China and their high frequency of contact with humans, proper advice should be given to the susceptible human populations in order to reduce the zoonotic transmission of this neglected disease.

\section{Conflict of interest}

There is no conflict of interests.

Acknowledgements. This study was supported by the Chengdu Giant Panda Breeding Research Foundation (CPF2014-10; CPF2014-14; CPF2015-4; CPF2017-12).

\section{References}

1. Ayinmode AB, Ogbonna NF, Widmer G. 2017. Detection and molecular identification of Cryptosporidium species in laboratory rats (Rattus norvegicus) in Ibadan, Nigeria. Annals of Parasitology, 63, 105-109.

2. Bitto A, Aldras A. 2009. Occurrence of Giardia and Cryptosporidium in muskrats in northeastern Pennsylvania and New Jersey. Journal of Environmental Health, 71, 20-26.

3. Björkman C, Lindström L, Oweson C, Ahola H, Troell K, Axén C. 2015. Cryptosporidium infections in suckler herd beef calves. Parasitology, 142, 1108-1114.

4. Certad G, Dupouy-Camet J, Gantois N, HammoumaGhelboun O, Pottier M, Guyot K, Benamrouz S, Osman M, Delaire B, Creusy C, Viscogliosi E, Dei-Cas E, Aliouat-Denis CM, Follet J. 2015. Identification of Cryptosporidium species in fish from Lake Geneva (Lac Léman) in France. PLoS One, 10, e0133047.

5. Chrisp CE, LeGendre M. 1994. Similarities and differences between DNA of Cryptosporidium parvum and C. wrairi detected by the polymerase chain reaction. Folia Parasitologica, 41, 97-100.

6. Čondlová Š, Horčičková M, Sak B, Květoňová D, Hlásková L, Konečný R, Stanko M, McEvoy J, Kváč M. 2018. Cryptosporidium apodemi sp. n. and Cryptosporidium ditrichi sp. n. (Apicomplexa: Cryptosporidiidae) in Apodemus spp. European Journal of Protistology, 63, 1-12.

7. Danišová O, Valenčáková A, Stanko M, Luptáková L, Hatalová E, Čanády A. 2017. Rodents as a reservoir of infection caused by multiple zoonotic species/genotypes of C. parvum, C. hominis, C. suis, C. scrofarum, and the first evidence of $C$. muskrat genotypes I and II of rodents in Europe. Acta Tropica, 172, 29-35.

8. Deng L, Li W, Yu X, Gong C, Liu X, Zhong Z, Xie N, Lei S, Yu J, Fu H, Chen H, Xu H, Hu Y, Peng G. 2016. First report of the human-pathogenic Enterocytozoon bieneusi from red-bellied tree squirrels (Callosciurus erythraeus) in Sichuan, China. PLoS One, 11, e0163605.

9. Deng L, Li W, Zhong Z, Gong C, Cao X, Song Y, Wang W, Huang X, Liu X, Hu Y, Fu H, He M, Wang Y, Zhang Y, Wu K, Peng G. 2017. Occurrence and genetic characteristics of Cryptosporidium hominis and Cryptosporidium andersoni in horses from Southwestern China. Journal of Eukaryotic Microbiology, 64, 716-720.

10. Deshpande AP, Jones BL, Connelly L, Pollock KG, Brownlie S, Alexander CL. 2014. Molecular characterization of Cryptosporidium parvum isolates from human cryptosporidiosis cases in Scotland. Parasitology, 142, 318-325.

11. Essid R, Menotti J, Hanen C, Aoun K, Bouratbine A. 2018. Genetic diversity of Cryptosporidium isolates from human populations in an urban area of Northern Tunisia. Infection, Genetics and Evolution, 58, 237-242.

12. Feng Y, Lal AA, Li N, Xiao L. 2011. Subtypes of Cryptosporidium spp. in mice and other small mammals. Experimental Parasitology, 127, 238-242.

13. Feng Y, Xiao L. 2017. Molecular epidemiology of cryptosporidiosis in China. Frontiers in Microbiology, 8, 1701.

14. Katarzyna D, Anna B, Malgorzata B, Edward S. 2005. Experimental transmission of Cryptosporidium parvum isolates from wild rodents and calves to laboratory bred common voles (Microtus arvalis). Acta Parasitologica, 50, 19-24.

15. Kenneth WT, Edward RA, Melvin RG, Neil M. 2000. Cryptosporidium parvum transport from cattle fecal deposits on California rangelands. Journal of Range Management, 53, 295-299.

16. Kváč M, Vlnatá G, Ježková J, Horčičková M, Konečný R, Hlásková L, McEvoy J, Sak B. 2018. Cryptosporidium occultus sp. n. (Apicomplexa: Cryptosporidiidae) in rats. European Journal of Protistology, 63, 96-104.

17. Lv C, Zhang L, Wang R, Jian F, Zhang S, Ning C, Wang H, Feng C, Wang X, Ren X, Qi M, Xiao L. 2009. Cryptosporidium spp. in wild, laboratory, and pet rodents in China: occurrence and molecular characterization. Applied and Environmental Microbiology, 75, 7692-7699.

18. Mehdi M, Zabiholah Z, Khadijeh K, Eshrat BK, Afsaneh MH, Jaber D, Tahereh R, Fathemeh T, Mostafa R. 2017. Natural intestinal Protozoa in Rodents (Rodentia: Gerbillinae, Murinae, Cricetinae) in Northwestern Iran. Iranian Journal of Parasitology, 12, 382-388.

19. Monireh G, Hamid R, Somayeh N, Fatemeh AK. 2016. Zoonotic and non-zoonotic parasites of wild rodents in Turkman Sahra, Northeastern Iran. Iranian Journal of Parasitology, 11, 350-357.

20. Ng-Hublin JS, Singleton GR, Ryan U. 2013. Molecular characterization of Cryptosporidium spp. from wild rats and 
mice from rural communities in the Philippines. Infection, Genetics and Evolution, 16, 5-12.

21. Nolan MJ, Jex AR, Koehler AV, Haydon SR, Stevens MA, Gasser RB. 2012. Molecular-based investigation of Cryptosporidium and Giardia from animals in water catchments in southeastern Australia. Water Research, 47, 1726-1740.

22. Perec-Matysiak A, Buńkowska-Gawlik K, Zaleśny G, Hildebrand J. 2015. Small rodents as reservoirs of Cryptosporidium spp. and Giardia spp. in south-western Poland. Annals of Agricultural and Environmental Medicine, 22, 1-5.

23. Qi M, Luo N, Wang H, Yu F, Wang R, Huang J, Zhang L. 2015. Zoonotic Cryptosporidium spp. and Enterocytozoon bieneusi in pet chinchillas (Chinchilla lanigera) in China. Parasitology International, 64, 339-341.

24. Retief JD. 2000. Phylogenetic analysis using PHYLIP. Methods in Molecular Biology, 132, 243-258.

25. Ryan U, Fayer R, Xiao L. 2014. Cryptosporidium species in humans and animals: current understanding and research needs. Parasitology, 141, 1667-1685.

26. Sergio SV, Fannie PC, Stefan DF, Juan PC. 2012. Primers to amplify flowering locus T (FT) transcript in mango (Mangifera indica) and their potential use in other angiosperms. Plant Omics, 5, 453-457.
27. Siński E, Bednarska M, Bajer A. 2013. The role of wild rodents in ecology of cryptosporidiosis in Poland. Folia Parasitologica, 45, 173-174.

28. Stenger BLS, Horčičková M, Clark ME, Kváč M, Čondlová Š, Khan E, Widmer G, Xiao L, Giddings CW, Pennil C, Stanko M, Sak B, McEvoy JM. 2017. Cryptosporidium infecting wild cricetid rodents from the subfamilies Arvicolinae and Neotominae. Parasitology, 145, 326-334.

29. Wielinga PR, de-Vries A, van der Goot TH, Mank T, Mars MH, Kortbeek LM, van-der-Giessen JW. 2008. Molecular epidemiology of Cryptosporidium in humans and cattle in the Netherlands. International Journal for Parasitology, 38, 809-817.

30. Yin J, Yuan Z, Shen Y, Zhang J, Jiang Y, Cao J. 2013. Molecular identification of Cryptosporidium spp. from animal sources in China. Journal of Infection in Developing Countries, 7, 1020-1022.

31. Zhao W, Wang J, Ren G, Yang Z, Yang F, Zhang W, Xu Y, Liu A, Ling H. 2018. Molecular characterizations of Cryptosporidium spp. and Enterocytozoon bieneusi in brown rats (Rattus norvegicus) from Heilongjiang Province, China. Parasites \& Vectors, 11, 313.

Cite this article as: Chai Y, Deng L, Liu H, Yao J, Zhong Z, Xiang L, Fu H, Shen L, Zhou Z, Deng J, Hu Y \& Peng G. 2019. First detection of Cryptosporidium spp. in red-bellied tree squirrels (Callosciurus erythraeus) in China. Parasite 26, 28.

\section{(0) PARASTE}

An international open-access, peer-reviewed, online journal publishing high quality papers on all aspects of human and animal parasitology

Reviews, articles and short notes may be submitted. Fields include, but are not limited to: general, medical and veterinary parasitology; morphology, including ultrastructure; parasite systematics, including entomology, acarology, helminthology and protistology, and molecular analyses; molecular biology and biochemistry; immunology of parasitic diseases; host-parasite relationships; ecology and life history of parasites; epidemiology; therapeutics; new diagnostic tools.

All papers in Parasite are published in English. Manuscripts should have a broad interest and must not have been published or submitted elsewhere. No limit is imposed on the length of manuscripts.

Parasite (open-access) continues Parasite (print and online editions, 1994-2012) and Annales de Parasitologie Humaine et Comparée (1923-1993) and is the official journal of the Société Française de Parasitologie. 